\title{
Retracted: Influence of Al Content on Degradation Behavior of Cu-Doped Mg-Al Alloys for Drill-Free Plugging Applications
}

\author{
Advances in Materials Science and Engineering \\ Received 19 November 2021; Accepted 19 November 2021; Published 24 December 2021 \\ Copyright $(\odot 2021$ Advances in Materials Science and Engineering. This is an open access article distributed under the Creative \\ Commons Attribution License, which permits unrestricted use, distribution, and reproduction in any medium, provided the \\ original work is properly cited.
}

Advances in Materials Science and Engineering has retracted the article titled "Influence of $\mathrm{Al}$ Content on Degradation Behavior of Cu-Doped Mg-Al Alloys for Drill-Free Plugging Applications" [1] due to concerns that appropriate permissions were not obtained for the publication of the data. The journal was contacted by a contributor to the data presented in the article, who raised concerns that key contributors were not listed as authors and were not consulted prior to the submission of the paper. The corresponding author contacted the journal separately to request the retraction of the article due to these concerns. Both parties additionally raised concerns with the reliability of the data, and the article is being retracted with the agreement of the authors and the editorial board.

\section{References}

[1] L. Kang, Y. Shi, X. Luo, and B. Liu, "Influence of Al Content on Degradation Behavior of Cu-Doped Mg-Al Alloys for DrillFree Plugging Applications," Advances in Materials Science and Engineering, vol. 2020, Article ID 8898669, 9 pages, 2020. 